\title{
Getting to Better Prescription Drug Information
}

\author{
Steven Woloshin, MD, MS ${ }^{1,2}$ and Lisa M. Schwartz, MD, MS

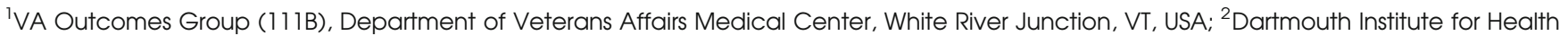 \\ Policy and Clinical Practice, Lebanon, NH, USA.
}

J Gen Intern Med 27(12):1582-4

DOI: $10.1007 / \mathrm{s} 11606-012-2222-2$

(C) Society of General Internal Medicine (Outside the USA) 2012

I $\mathrm{n}$ addition to alchemy, medicine, botany, astrology and the occult, the great Renaissance polymath Paracelsus was a master of sound bites. His statement, "all drugs are poisons" certainly grabs your attention. ${ }^{1}$ But what does it mean? That people should avoid all medications? Certainly not. Paracelsus devised quite a few medicines himself. He meant that when it came to medications, you have to be careful. Used correctly, they can save lives. Used wrongly, they can kill.

Five hundred years later, two articles in this issue of JGIM show how modern drug regulators, researchers, doctors and patients continue to grapple with Paracelsus' concern about medications.

In the first article, Cooper Bailey, et al. ${ }^{2}$ focus on an obvious - but surprisingly understudied - way to maximize the benefit and minimize the harms of medications: improving the instructions on pill bottles so patients take them correctly. The authors tested whether enhanced pill bottle instructions - previously shown to help English-speaking patients take prescribed medications correctly ${ }^{3}$ - worked for patients with limited English proficiency. Patients were randomized to receive pill bottles with either enhanced instructions based on health literacy "best practices" (take 2 pills in the morning and 2 pills at bedtime), or standard chain pharmacy instructions (TAKE TWO TABLETS TWICE DAILY). All instructions were translated into the patient's language (Chinese, Korean, Russian, Spanish or Vietnamese). These simple wording and formatting changes made a difference. The enhanced instructions improved understanding of how to take a single drug ( $83 \%$ vs. $66 \%$ placed pills into the correct time slot on a dosing tray), and how to take multiple drugs (median number of drugs correctly placed on a dosing tray: four out of five vs. three out of five).

"All drugs are poisons"1

Philippus Aureolus Theophrastus Bombastus von Hohenheim- Dr. Paracelsus (1493-1541)

The views expressed herein do not necessarily represent the views of the Department of Veterans Affairs or the United States Government.

Published online November 6, 2012
In the second article, Wolf, et al. ${ }^{4}$ examined another effort to maximize the safe use of drugs: Medication Guides. The guides are documents that pharmacies are required to distribute when dispensing certain prescription drugs. These documents, which are written by industry and approved by the US Food and Drug Administration (FDA), are meant to alert patients about especially serious side effects. Unfortunately, after reviewing 185 Medication Guides, Wolf, et al. concluded that they were "of little value to patients" because they were too complex and written at too high a reading level. In a second study reported in the same paper, these findings were confirmed: on average, primary care patients shown three Medication Guides were only able to correctly answer about half the comprehension questions asked.

Wolf calls for substantial revisions to Medication Guides. We agree. Fundamental changes in the presentation and content are needed to ensure that patients get the information that Medication Guides should communicate. Here are some suggestions based on the findings of Wolf et al., ${ }^{4}$ other recent literature, ${ }^{3,5-8}$ and our own work in this area over the past decade $:^{9-15}$

\section{BETTER PRESENTATION}

Unjumble the Order. Medication Guides are not well organized. They present a series of questions and answers about drugs, but the order is jumbled. Medication Guides list either a black box warning or other serious side effects before they even say what the drug is for. The remaining side effects (including other serious ones) are not listed until after indications, contraindications and "how to take the drug". To fix this problem, guides should begin with the indication. If the drug has a black box warning, it should appear next. Ideally, there would be a brief, prominent alert, something like "This drug carries a black box warning - the FDA's most serious level of warning -for heart attacks. See Serious side effect section for full description".

Use Tables. In consumer testing, the FDA found that the table format (used for over-the-counter drugs) outperformed both the "Question and Answer" format (used in Medication Guides) and the "Highlights" format (the structured table of contents, which now begins the label for prescribers). 
Specifically, the table format was associated with highest recall of side effects, the greatest confidence in finding and using information and the strongest consumer preference. ${ }^{5}$

\section{Structure By Indication Rather Than By Questions.}

Medication Guides also have an organizational quirk that makes them unnecessarily hard to use. FDA regulations allow only one Guide for a drug, but many drugs have multiple indications. Since the target population may differ markedly across indications (i.e., in terms of age, comorbidities, use of other drugs), the range and magnitude of drug side effects is likely to differ (as will benefit). Current Medication Guides are organized around questions (e.g., "What is the most important information I should know about Drug?" and "How should I take Drug?") rather than indication. It is easy for patients to lose track of where they are, or to assume that the information applies to all indications.

Cohen and Brown recently made this point in a critique of the Medication Guide for erythropoiesis-stimulating agents (ESAs), which are indicated for patients with anemia from cancer, as well as those with anemia from chronic kidney disease. ${ }^{8}$ The Guide obscures the different balance of benefits and harms of ESAs across these indications. Medication Guides should be redesigned so that they address each indication separately.

\section{BETTER CONTENT}

Do Not Sacrifice Key Information in the Name of "Readability". A basic principle of communication is the concept of readability - avoiding overly complex writing that can make it hard to reach the target audience. The problem is that enhancing readability often devolves into adopting arbitrary reading level goals (e.g., 4th or 8th grade level), and limiting vocabulary to common word lists. Unfortunately, this approach may lead to oversimplification which gives the illusion of improved communication (e.g., achieving a reading level goal), but in fact actually make things worse (failing to communicate key information).

This point was well illustrated when the FDA issued draft Guidance for Industry about how to disclose drug side effects in the brief summary of direct-to-consumer drug ads. ${ }^{16}$ The FDA issued an example for a hypothetical drug. To enhance readability, they translated the side effects in the professional label of "nightmares," "2 \% suicidal ideation rate," and "acute liver failure" to "vivid dreams," "severe depression," and "affect liver function" in the consumerfriendly version of the brief summary. At the time, Dr. Jerry Avorn commented that, "I worry about under the banner of user-friendliness, they seem to be selectively removing some of the severe side effects. It's not the conversion to lay language, it's the editing out of severe side effects." 17
The issue of readability applies to more than just the content of Medication Guides. It also applies to their evaluation. Using readability scores to judge the success of a guide is a mistake. The only reliable way to know if a Medication Guide really works is to test comprehension of key information directly (for example, do patients correctly recognize a drug's serious or life-threatening side effects?).

Quantify Benefit and Side-Effects. Numbers are also often sacrificed in trying to make communications consumerfriendly. But this is misguided. Patients vary in how they interpret words (e.g. your chance of impotence is low) and words alone create exaggerated risk perceptions. When numbers are presented clearly, they enhance patient's medical decisions. ${ }^{12,18}$ In fact, the FDA's own evidencebased user's communication guide says, "it is imperative to provide patients with numerical estimates of the risks and benefits associated with treatment options."

Nevertheless, the ESA Medication Guide, for example, starts as follows:

\section{What is the most important information I should know about Epogen? \\ Using Epogen can lead to death or other serious side effects.}

This guide-like all Medication Guides - names side effects, but never states how often they occur, making it hard for readers to decide how much to worry.

Nor does the guide provide any numbers about benefit. The ESA guide never provides any data about the drug's benefit: how many transfusions are avoided and, in the case of dialysis patients, how much quality of life improves. How can patients weigh benefit and harm unless they know the magnitude of each?

Inadequate communication of data about benefits and harms also plagues direct-to-consumer drug ads and professional drug labels. ${ }^{10,13}$ For example, the professional label for Ritalin - one of the drugs whose medication guide was tested in Wolfe's study - does not include any data on benefit.

Sadly, good data about both the benefits and harms of prescription drugs for a given indication are hard to find. The data exist but are practically inaccessible, buried inside lengthy, poorly organized FDA review documents. We have developed a format to bring these data to light called the Drug Facts Box, modeled on FDA's nutrition facts boxes. The central feature of the box is a table presenting the chance of various outcomes with and without the drug. A body of research, including three national randomized trials, shows that the box effectively communicates drug benefit and harm data. In one randomized trial, for example, $68 \%$ of people randomized to see direct-to-consumer ads with drug boxes chose the objectively better of two heartburn drugs compared to $31 \%$ of people seeing only the standard ads. ${ }^{12}$ 
The FDA's Risk Communication Advisory Committee ${ }^{19}$ - and Congress ${ }^{20}$ - have called on FDA to adopt the Drug Facts Box in Medication Guides, in other forms of consumer medical information, and in the professional label. Unfortunately, the FDA has said it needs an additional 3-5 years to study the evidence before it can consider moving ahead.

The current state of prescription drug information is pretty grim. But there are evidence-based solutions to improve patient understanding of how well medications work and how to take them as prescribed. Fortunately, we do not need an alchemist to work miracles. We just need policy makers to implement sensible strategies that work.

Corresponding Author: Lisa M. Schwartz, MD, MS; VA Outcomes Group (111B), Department of Veterans Affairs Medical Center, White River Junction, VT 05009, USA (e-mail: Lisa.schwartz@ dartmoutn.edu).

\section{REFERENCES}

1. Avorn J. Powerful medicines: The benefits, risks and costs of prescription drugs. New York: Random House; 2005.

2. Cooper Bailey S, Sarkar U, Hm Chen A. Evaluation of language concordant, patient-centered drug label instructions. J Gen Intern Med. 2012; doi:10.1007/s11606-012-2035-3.

3. Wolf M, Davis T, Curtis L. Effect of standardized, patient-centered label instructions to improve comprehension of prescription drug use. Med Care. 2011;49:5.

4. Wolf M, King J, Wilson E. Usability of FDA-approved medication guides. J Gen Intern Med. 2012 ; doi:10.1007/s11606-012-2068-7.

5. Aikin K, O'Donoghue A, Swasy J, Sullivan H. Randomized trial of risk information formats in direct-to-consumer prescription drug advetisements. Med Decis Making. 2011;31:E23-33.
6. Fischhoff B. Communicating risks and benefits: An evidence-based user's guide. In: Brewer N, Downs J, eds. U.S. Food and Drug Administration, U.S Department of Health and Human Services; 2011

7. Nicolson D, Knapp P, Raynor D, Spoor P. Written information about individual medicines for consumers. Cochrane Database Syst Rev. 2009 (11).

8. Cohen R, Brown R. The US Food and Drug Administration's Risk Evaluation and Mitigation Strategy (REMS) Program in practice: does it really inform patients and limit risk? Am J Kidney Dis. 2012;59:3.

9. Schwartz L, Woloshin S, Welch $\mathbf{H}$. The drug facts box: providing consumers with simple tabular data on drug benefit and harm. Med Decis Making. 2007;27.

10. Schwartz LM, Woloshin S. Lost in transmission-FDA drug information that never reaches clinicians. N Engl J Med. 2009;361:1717-20.

11. Schwartz LM, Woloshin S. Communicating uncertainties about prescription drugs to the public. A national randomized trial. Arch Intern Med. 2011;171:1463-8.

12. Schwartz LM, Woloshin S, Welch HG. Using a drug facts box to communicate drug benefits and harms: two randomized trials. Ann Intern Med. 2009;150:516-27.

13. Woloshin S, Schwartz L, Tremmel J, Welch H. Direct to consumer drug advertisements: what are Americans being sold? Lancet. 2001;358:1141-6.

14. Woloshin S, Schwartz $\mathbf{L}$, Welch $\mathbf{H}$. The value of benefit data in direct-toconsumer drug ads. Health Affairs 2004:W234-45.

15. Woloshin S, Schwartz LM. Communicating data about the benefits and harms of treatment: a randomized trial. Ann Intern Med. 2011;155:87-96.

16. U.S. Food and Drug Administration. Disclosing risk information in consumer-directed print advertisements: Brief summary, Example of fictitious highlights of prescribing information, Example of fictitional highlights of prescribing information (based on proposed physicianlabeling rule) translated in consumer-friendly language and formatted for use in consumer directed. February 4, 2004. Available at: http:// www.fda.gov/Drugs/GuidanceComplianceRegulatoryInformation/ Guidances/ucm064956.htm. Accessed August 10, 2012.

17. Kritz FL. FDA on drug ads: less is more. Washington Post. 2004; 10:2004.

18. Stacey D, Bennett C, Barry M, Col N, Eden K, Holmes-Rovner M, et al. Decision aids for people facing health treatment or screening decisions. Cochrane Database Syst Rev. 2011(10).

19. Minutes of the risk communication advisory committee. FDA . April $30-$ May 1, 2009 http://www.fda.gov/downloads/AdvisoryCommittees/ CommitteesMeetingMaterials/RiskCommunicationAdvisoryCommittee/ UCM190625.pdf.

20. Public Law 111 - 148. Patient Protection and Affordable Care Act. Section 3507. Enacted March 23, 2010. 